\title{
The effect of halloysite modification combined with in situ matrix modifications on the structure and properties of polypropylene/halloysite nanocomposites
}

\author{
V. Khunova ${ }^{1 *}$, J. Kristóf $f^{2}$, I. Kelnar ${ }^{3}, J$. Dybal $^{3}$ \\ ${ }^{1}$ The Slovak University of Technology, Faculty of Chemical and Food Technology, Institute of Polymer Materials, \\ Radlinského 9, 81237 Bratislava, Slovakia \\ ${ }^{2}$ Institute of Environmental Engineering, University of Pannonia, H-8200 Veszprém, P.O. Box 158, Hungary \\ ${ }^{3}$ Institute of Macromolecular Chemistry, Academy of Science of the Czech Republic, Heyrovsky Sq. 2, 16206 Prague, \\ Czech Republic
}

Received 13 November 2012; accepted in revised form 4 February 2013

\begin{abstract}
The effect of various modifications/intercalations of halloysite and the combination of these modifications with in situ PP matrix modification was investigated with respect to the structure and properties of the polypropylene/halloysite nanocomposites. Hexadecyl-tri-methyl-ammonium-bromide (HEDA), 3-aminopropyltrimethoxysilane and urea were used as the intercalators/modifiers. The best intercalation was found for urea, although an unexpected insignificant impact on the mechanical properties also resulted as a consequence of the urea polarity and the significant decrease in PP crystallinity. However, the simultaneous application of 4,4'-diphenylmethylene dimaleinimide (DBMI) brought about an increase in the mechanical behavior by increasing the halloysite/PP affinity as a result of in situ matrix modification. This effect was further supported by coupling between the PP and halloysite (HNT) in the system containing urea-intercalated HNT. This can be explained by the occurrence of a urea-supported reaction between the imide ring of DBMI and the OH groups of the HNT, which resulted in the best mechanical behaviors achieved in this study.
\end{abstract}

Keywords: nanocomposites, polypropylene, halloysite, modification

\section{Introduction}

The significant effort devoted to the development of polymer nanocomposites based on layered silicates has resulted in tremendous progress toward our understanding of the structure and properties of these scientifically and industrially important materials. However, several thermodynamic obstacles remain to be solved before the wide application of polymer/clay nanocomposites on the industrial scale can be realized [1-3].

Recently, an exponentially increasing number of papers have been published on the successful application of natural halloysite (HNT) in nanocompos- ites based on different polymer matrices [4]. In a recent review paper [5], a number of examples were given, documenting the significant potential of halloysite to compete with montmorillonite (MMT), which is currently the most commercially exploited clay for the preparation of polymer nanocomposites. This is generally due to the relative ease with which halloysite can be dispersed in polymer matrices in addition to its abundance, availability and biocompatibility.

Halloysite is naturally occurring aluminosilicate clay, frequently with a hollow tubular morphology [6]. The two main polymorphs of halloysite are the

\footnotetext{
${ }^{*}$ Corresponding author, e-mail: viera.khunova@stuba.sk

(C) BME-PT
} 
hydrated form, $\mathrm{Al}_{2} \mathrm{Si}_{2} \mathrm{O}_{5}(\mathrm{OH})_{4} \cdot 2 \mathrm{H}_{2} \mathrm{O}$, with a basal distance of approximately $10 \AA$ and the dehydrated form, $\mathrm{Al}_{2} \mathrm{Si}_{2} \mathrm{O}_{5}(\mathrm{OH})_{4}$, which is identical to kaolinite. The hydrated form is irreversibly converted to the dehydrated form upon drying below $100^{\circ} \mathrm{C}$. Water loss sharpens the basal reflections and reduces the basal d-spacings to approximately $7.2 \AA$, although this value is never so small as that of typical kaolinite (7.14 ̊) [7]. In the hydrated halloysite, the TO sheets, which are double layers consisting of Sicentered tetrahedral and Al-centered octahedral layers, are separated from each other by a water monolayer. Due to mismatch between the siloxane and gibbsite layers, halloysite occurs in the form of nanotubes [8].

A further difference between the layered silicatelike montmorillonite (MMT) and halloysite is the significantly lower cation exchange capacity (CEC) of HNT for modification via ionic exchange.

However, in halloysite, nanocomposites with highly polar polymer contents [9-12], such as PVC [9, 10], PA [11, 12], or epoxy [13], require no modification/ treatment of the halloysite for the preparation of melt-mixed polymer nanocomposites with well distributed HNT. With non-polar polyolefins such as $\mathrm{PP}$, due to the highly hydrophobic nature of PP, it is necessary to modify not only the halloysite [14-17], but also the polymer matrix to increase the polarity of PP [18-21]. Additionally, modification of halloysite by $\gamma$-metacryloxypropyl-trimethoxysilane leads to enhanced thermal stability and decreases flammability [22]. An alternative approach for increasing the interfacial interactions is the use of electron transferring modifiers. Examples of electron-transferring modifiers $[23,24]$ used in PP/halloysite composites include 2-bis(2-benzoxazolyl)tiophene [23] and N-cyclohexyl-2-benzothiazole sulfonamide [24]. A further example utilizes hydrogen bond bridged halloysite with polypropylene; this can be achieved with the use of melamine, diphenyl guanine, 2,4,6-trimercapto-s-triazine, melamine cyanuric acid, tri-(2-hydroxyethyl)isocyanurate or $\beta$ cyclodextrin [25]. The authors documented a significant improvement in the resulting end use properties of the PP composites containing $30 \mathrm{wt} \%$ halloysite. The last referred example of $\mathrm{PP} /$ halloysite composite modification was carried out with bis-2hydroxyethyl, quaternary ammonium solutions [26]. However, only negligible increases in the mechanical properties were observed.
In our earlier works, we documented [27-30] an effective alternative for increasing the PP polarity by the addition of pre-fabricated maleated polypropylene for in situ modification, using bifunctional compounds such as 4,4'-diphenylmethylene dimaleinimide (DBMI) and 1,3-phenylene dimaleimide (BMI).

This work highlights the effects of halloysite modification by hexa-decyl-tri-methyl-ammonium-bromide, 3-aminopropyltrimethoxysilane and urea individually as well as in combination using in situ modification of the PP matrix by 4,4'-diphenylmethylene dimaleinimide (DBMI).

\section{Experimental}

\subsection{Materials}

Halloysite was recovered from Biela Hora, Michalovce, Slovakia.

Before modification, the halloysite was ground into powder using a laboratory ball mill. Next, the powdered halloysite was purified and sieved to obtain a fraction smaller than 50 microns.

Polypropylene homopolymer (type $575 \mathrm{P}$ ) with a melt flow rate of $11.0 \mathrm{~g} / 10 \mathrm{~min}\left(230^{\circ} \mathrm{C} / 2.16 \mathrm{~kg}\right)$ was provided by Sabic, Sittard-Geleen, Netherlands.

The silane used was 3-aminopropyltrimetoxysilane, provided by Sigma Aldrich, USA.

The alkylamine used was hexa-decyl-tri-methylammonium-bromide (HEDA), obtained from Sigma Aldrich, USA.

Analytical grade urea was purchased from Merck, Hungary.

The reactive modifier was 4,4'-diphenyl methylenedimaleinimide (DBMI), from VUCHT, Bratislava, Slovakia.

\subsection{Halloysite modification}

\subsubsection{Halloysite modification by}

hexa-decyl-tri-methyl-ammonium bromide

The purified ground halloysite was treated in 5\% solution of hexa-decyl-tri-methyl-ammonium-bromide (HEDA) at $80^{\circ} \mathrm{C}$ for $24 \mathrm{~h}$. After filtration, the HNTs were dried in a vacuum oven at $60^{\circ} \mathrm{C}$ for $24 \mathrm{~h}$. The dried powder was ground and sieved again [19].

\subsubsection{Halloysite modification by 3-aminopropyltrimethoxysilane}

The modification of halloysite by 3 -aminopropyltrimethoxysilane was performed by adding silane 
A1100 in water/ethanol solution adjusted by acetic acid to $\mathrm{pH}$ 5.0. The detailed procedure for this modification is given in [17].

\subsubsection{Halloysite intercalation by urea}

The intercalation of urea into the halloysite was performed by mechanochemical means (dry grinding). A $10 \mathrm{~g}$ mixture of the clay and urea (mixed in a 2:1 ratio) was generated using a Fritsch Pulverisette $5 / 2$ type laboratory planetary mill. Milling was performed for $30 \mathrm{~min}$ in an $80 \mathrm{~cm}^{3}$ capacity stainless steel bowl using 29 (110.3 g total) stainless steel balls (10 $\mathrm{mm}$ diameter each). The rotation speed was $374 \mathrm{rpm}$.

\subsection{Composite preparation}

The composites were formed from polypropylene and untreated and/or intercalated halloysite (at a ratio of $5 \mathrm{wt} \%$ ) via melt mixing in a Brabender W50-E chamber. In the case of in situ matrix modification to increase PP polarity, $1 \%$ DBMI was added [27]. The mixing temperature was $200^{\circ} \mathrm{C}$, and the rotor speed was $200 \mathrm{rpm}$. Dog bone-shaped specimens (a gauge length of $40 \mathrm{~mm}$ ) were prepared in a laboratory micro-injection molding machine (DSM). The barrel temperature was $200^{\circ} \mathrm{C}$, and the mold temperature was $70^{\circ} \mathrm{C}$.

\subsection{Analysis and characterization}

Wide-angle X-ray diffraction patterns (WAXS) were collected using a powder diffractometer (HZG/4A from Freiberger Präzisionsmechanik GmbH, Germany), using monochromatic $\mathrm{Cu} \mathrm{K} \alpha$ radiation. Analyses were performed on the surface of the compression-molded sheets. X-ray diffraction (XRD) analyses were carried out on a Philips PW 3710 type diffractometer equipped with a PW 3020 vertical goniometer and a curved graphite diffracted beam monochromator. The radiation applied was $\mathrm{Cu} \mathrm{K} \alpha$, generated from a broad-focus $\mathrm{Cu}$ tube operated at $50 \mathrm{kV}$ and $40 \mathrm{~mA}$. The samples were measured in a continuous scan mode with $0.02 \%$ scanning speed. Data collection and evaluation were performed with PC-APD 3.6 software. Back-packed mounts of finely powdered samples were used to eliminate preferential orientation.
Transmission electron microscopy (TEM) observations were performed on a TESLA BS 300 combined scanning and transmission electron microscope, using ultrathin $(60 \mathrm{~nm})$ sections, which were cut under liquid $\mathrm{N}_{2}$ with an Ultracut UCT (Leica) ultramicrotome.

Tensile tests were carried out at $22^{\circ} \mathrm{C}$ using an Instron 5800 apparatus at a crosshead speed of $20 \mathrm{~mm} / \mathrm{min}$. $E$ modulus and stress-at-break $\left(\sigma_{\mathrm{b}}\right)$ were evaluated. The average data from at least eight replicates were reported.

ATR FTIR spectra were collected on a Nicolet Nexus 870 FTIR spectrometer purged with dry air and equipped with a MCT detector. The samples were measured on a horizontal micro-ATR Golden Gate unit (SPECAC) with a diamond prism. The spectra were processed with advanced ATR correction using the OMNIC software.

DRIFT spectra were recorded by means of a Bruker Equinox 55 type FTIR spectrometer equipped with a room-temperature DTGS detector and a Harrick DRIFT adapter at a resolution of $2 \mathrm{~cm}^{-1}$. In all cases, 512 spectra (scans) were summed. For the halloysite samples, $\mathrm{KBr}$ was used as the background, while for the polymer composites the background spectra were recorded with an aluminum mirror.

The model quantum mechanical calculations were performed with density functional theory (DFT) using the Gaussian 03 program package. The B3LYP functional and the 6-31G $(d)$ basis sets were used and the optimizations were unconstrained. Vibrational frequencies of the normal modes were scaled by the standard scaling factor 0.96 [31].

\section{Results and discussion}

\subsection{Characterization of halloysite}

The chemical composition of the studied halloysite, which was recovered from location Biela Hora, Michalovce, Slovakia is given in Table 1.

The chemical composition is similar to that of other halloysites/kaolinites. The amount of dehydroxylation water is $14.32 \%$, which is very close to the theoretical value (13.96\%).

From the TEM analyses (Figure 1) it is evident, that the halloysite Biela Hora has a favorable for polymer composites tubular particle shapes with diam-

Table 1. The chemical composition of the halloysite Biela Hora, Slovakia

\begin{tabular}{|c|c|c|c|c|c|c|c|c|c|}
\hline Composition & $\mathbf{S i O}_{\mathbf{2}}$ & $\mathbf{A l}_{2} \mathbf{O}_{\mathbf{3}}$ & $\mathbf{F e}_{\mathbf{2}} \mathbf{O}_{\mathbf{3}}$ & $\mathbf{C a O}$ & $\mathbf{M g O}$ & $\mathbf{K}_{\mathbf{2}} \mathbf{O}$ & $\mathbf{N a}_{\mathbf{2}} \mathbf{O}$ & $\mathbf{T i O}_{\mathbf{2}}$ & $\mathbf{L O I}$ \\
\hline $\mathrm{wt} \%$ & 45.48 & 33.74 & 1.27 & 0.39 & 0.10 & 0.02 & 0.02 & 0.05 & 17.41 \\
\hline
\end{tabular}




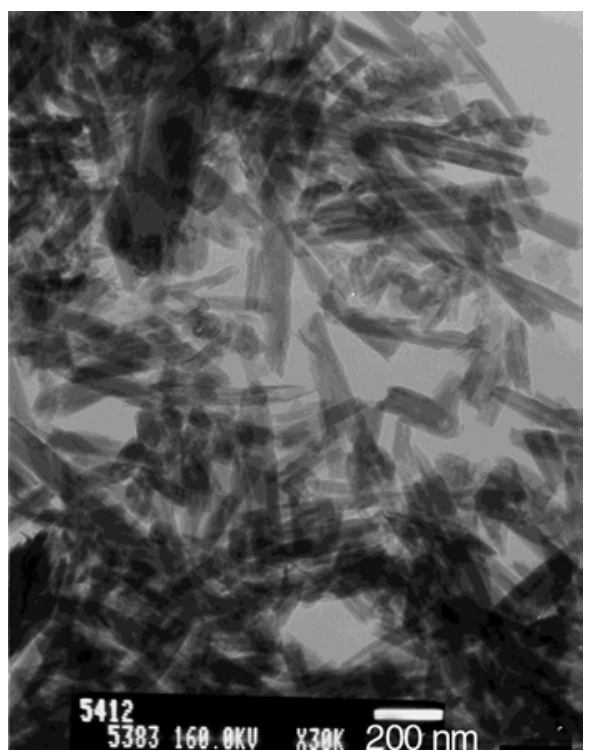

Figure 1. TEM micrographs of pristine halloysite, Biela Hora, Slovakia

eter $30-60 \mathrm{~nm}$ and the length from 200 up to $400 \mathrm{~nm}$.

The FTIR (Figure 2) spectrum of the halloysite confirms that the band at $3695 \mathrm{~cm}^{-1}$ belongs to the stretching vibration of the inner surface $\mathrm{OH}$ groups, while the stretching band of the inner groups occurs at $3622 \mathrm{~cm}^{-1}$. The inner surface $\mathrm{OH}$ groups are connected to the Al-centered octahedral sheets and form hydrogen bonds with the oxygen sheet in the next double layer. The other two inner surface $\mathrm{OH}$ groups at approximately 3650 and $3670 \mathrm{~cm}^{-1}$ cannot be observed, which is typical of halloysites. The stretching band of the inner $\mathrm{OH}$ groups, which is located in the plane common to both the tetrahedral and octahedral sheets, is not accessible by the reagent molecules, thus the peak always appears at the same position. The bands at 3603 and $3554 \mathrm{~cm}^{-1}$ belong to isolated and adsorbed water molecules, respec-

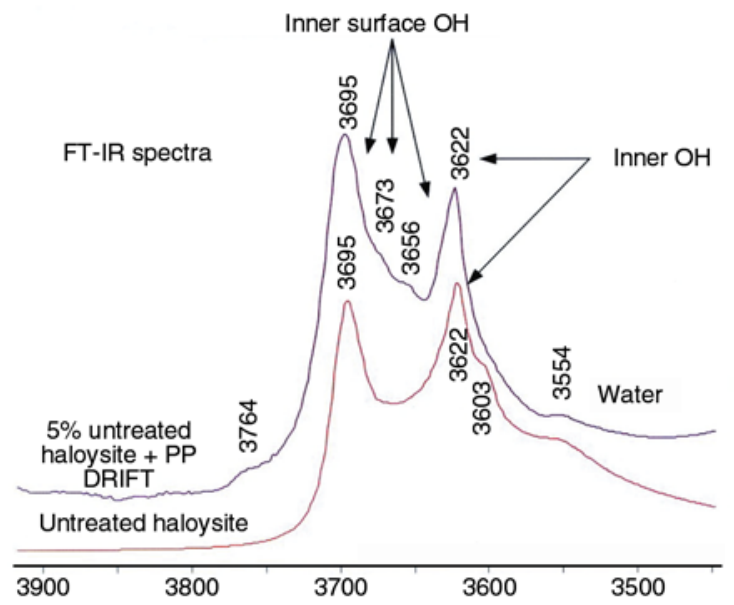

Figure 2. FTIR analysis of the halloysite

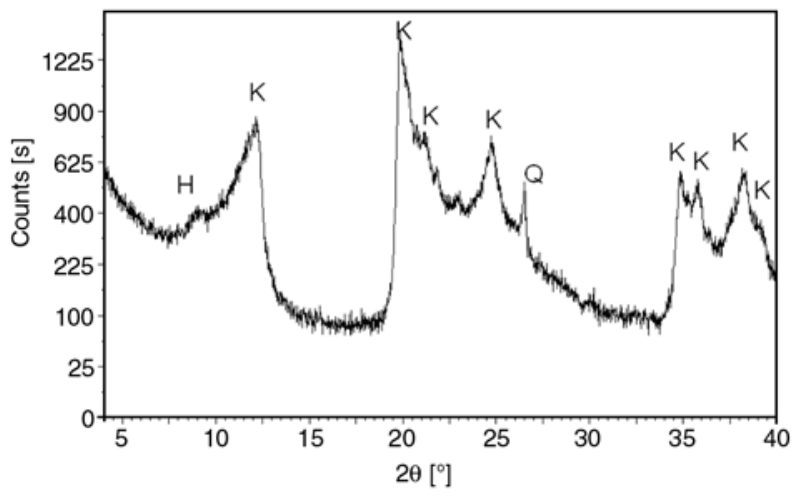

Figure 3. X-ray diffraction patterns of the pristine halloysite (H: halloysite; K: kaolinite/dehydrated halloysite; Q: quartz)

tively. Once the untreated halloysite is mixed into PP at 5\% loading, the DRIFT spectrum is significantly modified. The hidden inner $\mathrm{OH}$ bands appeared at 3673 and $3656 \mathrm{~cm}^{-1}$ (similar to kaolinites), and the band at $3603 \mathrm{~cm}^{-1}$ (assigned to the isolated water molecules) disappeared. This observation indicates that the halloysite is present in the PP matrix in dehydrated form. The presence of the shoulder peak at $3764 \mathrm{~cm}^{-1}$ is difficult to explain. This feature is either an overtone or a combination band.

The XRD pattern of the original unmodified halloysite clay displays 001 reflections at 10.2 and $7.2 \AA$ (Figure 3). The $10.2 \AA$ reflection belongs to the intact portion of halloysite, which possesses a water monolayer between the clay double layers, while the $7.2 \AA$ band represents dehydrated halloysite. Based on the XRD pattern, the dehydrated form constitutes approximately $80 \%$ of the mineral.

\subsection{Influence of modification on the HNT structure}

As noted earlier, two inevitable steps are necessary to prepare polymer nanocomposite materials with advanced properties. These steps include intercalation of the clay and the establishment of sufficient interfacial adhesion between the polymer matrix and the filler surface. This study compares the influence of 3 distinct types of modifiers (alkylamine, silane and urea) on the structure from the perspective of intercalation/delamination of the halloysite and fillers; this process was used to establish successful halloysite modification/intercalation.

As evident from Table 2 and Figure 4, the modification of halloysite by HEDA and silane caused no alteration to the basal d-spacing or the halloysite structure. Unlike the alkylamine and silane treat- 
Table 2. The effect of modification on the basal d-spacing of the PP/HNT nanocomposites

\begin{tabular}{|l|c|c|}
\hline \multicolumn{1}{|c|}{ Sample } & $\begin{array}{c}\mathbf{2 \theta} \\
{\left[{ }^{\circ}\right]}\end{array}$ & $\begin{array}{c}\text { d-spacing } \\
{[\AA \mathbf{\AA}]}\end{array}$ \\
\hline PP + 5 wt\% untreated HNT & 12.170 & 7.27 \\
\hline PP + 5 wt\% HNT modified urea & 8.140 & 10.85 \\
\hline PP + 5 wt\% HNT modified urea + 1 wt\% DBMI & 8.115 & 10.89 \\
\hline PP + 5 wt\% HNT modified HEDA & 12.200 & 7.24 \\
\hline PP + 5 wt\% HNT modified HEDA + 1 wt\% DBMI & 12.175 & 7.29 \\
\hline PP + 5 wt\% HNT modified silane & 12.130 & 7.29 \\
\hline PP + 5 wt\% HNT modified silane + 1 wt\% DBMI & 12.185 & 7.29 \\
\hline
\end{tabular}

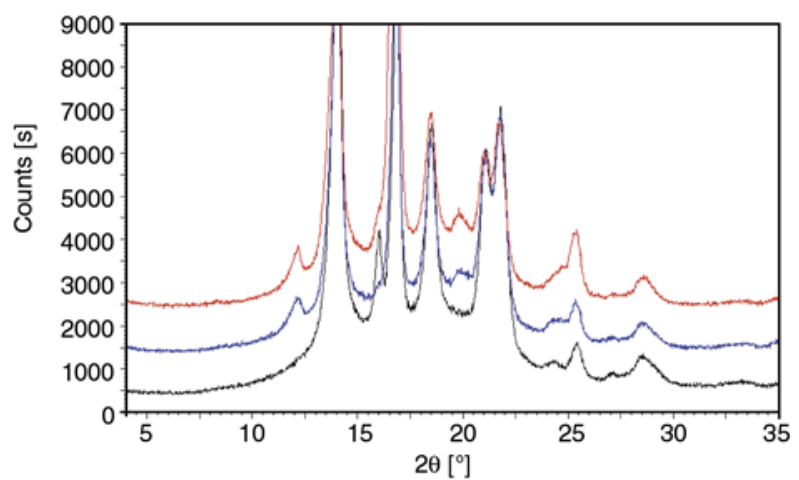

Figure 4. XRD patterns of the unfilled PP (black line), PP containing $5 \mathrm{wt} \%$ intercalated by HEDA (blue) and PP containing of $5 \mathrm{wt} \%$ intercalated by HEDA and $1 \mathrm{wt} \%$ DBMI (red line)

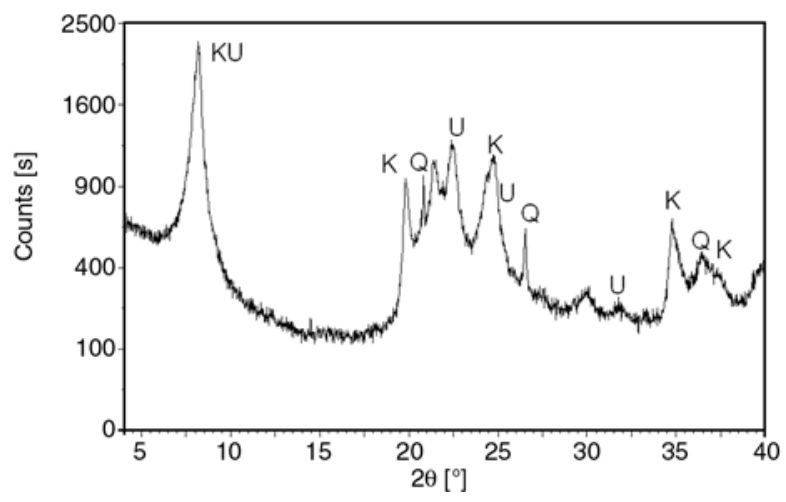

Figure 5. X-ray diffraction pattern of the urea-intercalated halloysite (H: halloysite; K: kaolinite/dehydrated halloysite; Q: quartz, U:urea)

ments, the modification of halloysite by urea resulted in a significant increase of the d-spacing. As evident from Figure 5 (approximately no intensity remains at the $7.27 \AA$ peak), an almost complete expansion of the double layers has occurred as a result of urea intercalation.

\subsection{Effect of HNT modification on the properties of the PP nanocomposites}

From Table 3, which shows the mechanical behavior of the nanocomposites containing $5 \mathrm{wt} \% \mathrm{HNT}$, it can be observed that the addition of untreated hal-
Table 3. The effects of the HEDA, silane and urea modifications on the mechanical properties of the HNT/PP nanocomposites

\begin{tabular}{|l|c|c|}
\hline \multicolumn{1}{|c|}{ Blend composition } & $\begin{array}{c}\boldsymbol{\sigma}_{\mathbf{b}} \\
{[\mathbf{M P a}]}\end{array}$ & $\begin{array}{c}\mathbf{E} \\
{[\mathbf{M P a}]}\end{array}$ \\
\hline Neat PP & $36.3 \pm 0.4$ & $1340 \pm 45$ \\
\hline $\mathrm{PP}+5 \mathrm{wt} \%$ untreated HNT & $36.5 \pm 0.4$ & $1440 \pm 84$ \\
\hline $\mathrm{PP}+5 \mathrm{wt} \%$ HNT modified HEDA & $36.5 \pm 0.3$ & $1547 \pm 35$ \\
\hline $\mathrm{PP}+5 \mathrm{wt} \%$ HNT modified silane & $36.2 \pm 0.6$ & $1495 \pm 65$ \\
\hline $\mathrm{PP}+5 \mathrm{wt} \%$ HNT modified urea & $36.5 \pm 0.8$ & $1449 \pm 30$ \\
\hline
\end{tabular}

loysite to the PP caused an insignificant influence on the mechanical properties, which has been found in similar studies using other HNT sources [14, 15]. This can be explained by the low affinity between the filler particles and the polymer matrix, which was also confirmed by the presence of relatively rough HNT particles (Figures 6a-6c). Furthermore, as indicated by the DSC results, the presence of the HNT induced a detrimental effect on the matrix, evidenced as a reduction in matrix crystallinity (Table 4).

The modification of halloysite by HEDA resulted in an increased modulus without a complementary increase in tensile strength (Table 3). The low increase in the d-spacing values (Table 2) indicates the (low) extent to which modification was achieved. Moreover, by taking into account the significant nucleating activity of HEDA on PP, as documented by DSC (Table 4), the main benefit of HEDA appears to be compensation of the reduced matrix crystallinity. As mentioned above, the crystallinity was reduced by the presence of the neat HNT itself. Similar results were found for the composites containing silane-modified HNT (Table 3): both negligible enhancements in the mechanical properties and the d-spacing values (Table 2) were found, corresponding with the low extent of modification achieved in this case, as well.

In the case of urea-modified halloysite, the significant increase in the d-spacing (Table 2) indicates that this procedure yielded the best intercalation abil- 


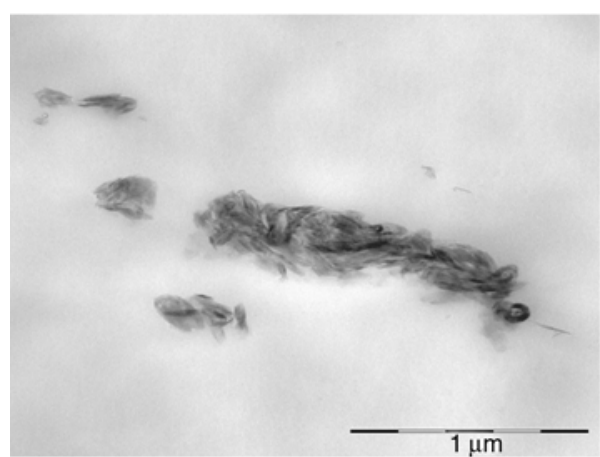

a)

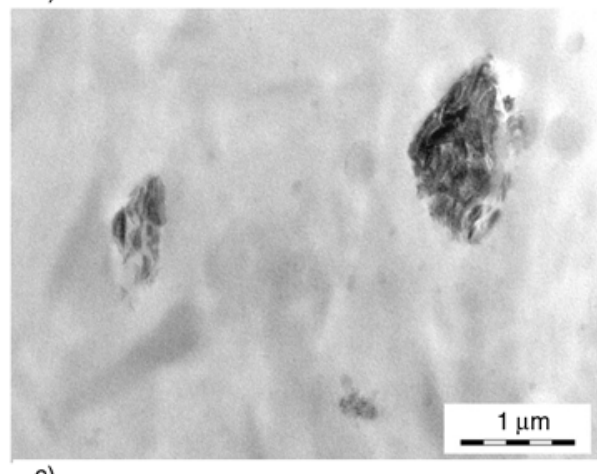

c)

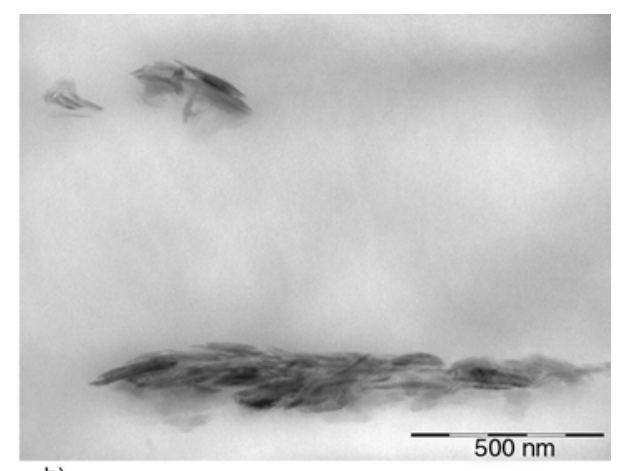

b)

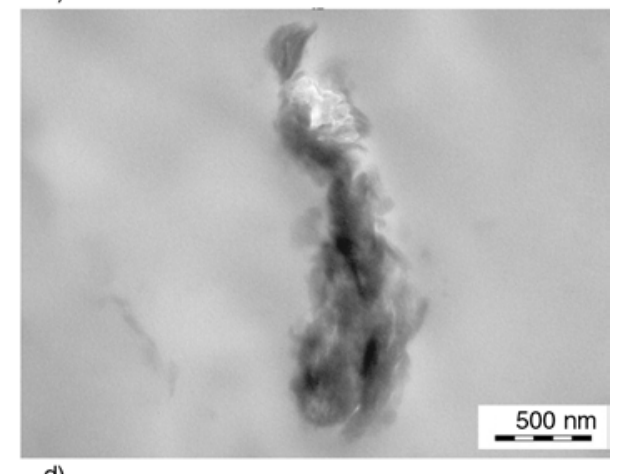

d)

Figure 6. TEM micrographs of the untreated PP/halloysite composites (a, b) and the PP/urea- intercalated halloysite composites modified by DBMI (c, d)

Table 4. Influence of $5 \mathrm{wt} \%$ of halloysite on PP crystallinity

\begin{tabular}{|c|c|c|c|}
\hline Sample & $\mathbf{T}_{\mathbf{m}}{ }^{*}$ & $\Delta \mathbf{H}^{*}$ & $\begin{array}{c}\text { Crystallinity } \\
{[\%]}\end{array}$ \\
\hline Neat PP & 166.0 & 105.0 & 46.1 \\
\hline $\mathrm{PP}+5 \mathrm{wt} \%$ untreated $\mathrm{HNT}$ & 163.0 & 88.6 & 41.0 \\
\hline $\mathrm{PP}+5 \mathrm{wt} \%$ untreated $\mathrm{HNT}+1 \mathrm{wt} \%$ DBMI & 164.4 & 91.1 & 42.2 \\
\hline $\mathrm{PP}+5 \mathrm{wt} \%$ untreated $\mathrm{HNT}+2 \mathrm{wt} \%$ DBMI & 159.9 & 87.7 & 40.3 \\
\hline $\mathrm{PP}+5 \mathrm{wt} \%$ untreated $\mathrm{HNT}+3 \mathrm{wt} \%$ DBMI & 162.9 & 94.0 & 43.2 \\
\hline PP $+5 w t \%$ HNT modified HEDA & 162.7 & 94.7 & 43.5 \\
\hline $\mathrm{PP}+5 \mathrm{wt} \%$ HNT modified HEDA + $1 \mathrm{wt} \%$ DBMI & 159.7 & 81.3 & 37.3 \\
\hline $\mathrm{PP}+5 \mathrm{wt} \%$ HNT modified silane & 166.1 & 122.8 & 56.3 \\
\hline $\mathrm{PP}+5 \mathrm{wt} \%$ HNT modified silane $+1 \mathrm{wt} \%$ DBMI & 165.0 & 76.6 & 35.8 \\
\hline $\mathrm{PP}+5 \mathrm{wt} \%$ HNT modified urea & 170.0 & 48.0 & 22,3 \\
\hline $\mathrm{PP}+5 \mathrm{wt} \%$ HNT modified urea $+1 \mathrm{wt} \%$ DBMI & 170.0 & 55.5 & 25.5 \\
\hline
\end{tabular}

ity among the modifiers applied. Hence, the behavior of the PP composites containing urea-modified HNT was highly unexpected in that we did not observe any improvement in the investigated mechanical properties (Table 3 ). One reason for this might be the identical d-spacings of both compounds (urea-modified halloysite and urea-modified halloysite/PP nanocomposites), indicating the low extent to which the PP chains were able to intercalate into the halloysite structure (Table 2). This was likely due to the unfavorable polarity (hydrophilicity) of this modification, which yielded a low affinity to PP.
The effect can be clearly seen in the DSC results (Table 4), which indicate the presence of a significant negative effect of the urea (intercalated into the HNT) on crystallinity and thus the mechanical parameters of PP.

These results indicate that, to achieve more favorable mechanical behavior, simultaneous modification of the PP matrix is necessary. Based on our earlier work, for this purpose, we used a reactive modifier, 4,4'-diphenyl methylene-dimaleinimide (DBMI) [27-30]. 


\subsection{Effect of in situ PP matrix functionalization on the modified HNT/PP composites}

From Table 5, it is apparent that modification with DBMI caused an increase in the strength and the modulus in all nanocomposites studied. This finding is in agreement with the highly effective nature of this reactive interfacial modifier, which also has been found for other composite systems [27-30]. From Table 4, it is evident that DBMI does not affect the crystallinity of the PP matrix.

Although in each of the PP composites containing untreated HNT, alkylamine (HEDA)-treated HNT and silane-treated HNT, the increase in the matrix polarity due to DBMI modification was comparable, a more significant increase in the studied properties was observed for the urea-treated halloysite. In this case, urea provides hydrogen bonds, which link the HNT with the modified PP. At the same time, DBMI acts as a coupling agent due to parallel linking to HNT facilitated by imide ring opening due to the presence of urea followed by reaction with the OH groups of the HNT.

This assumption was confirmed by the FTIR spectra (Figure 7), which demonstrates that, in comparison to pure HNT/PP, the application of DBMI to $\mathrm{HNT} / \mathrm{PP}$ yields a new band at $1514 \mathrm{~cm}^{-1}$ (Figures $7 \mathrm{a}$ and $7 \mathrm{~b}$ ). This new band was assigned to the $\mathrm{C}=\mathrm{C}$ double bond in the imide ring. When additional urea is present in the mixture, this band is shifted from 1514 to $1495 \mathrm{~cm}^{-1}$ (Figure 7c). This shift indicates opening of the imide ring, as confirmed by the DFT (density functional theory) quantum mechanical calculations (Figure 8).

With respect to the model structure shown in Figure $8 \mathrm{a}$, the calculated frequency of the band corresponding to the imide ring is $1501 \mathrm{~cm}^{-1}$. Here, it should be noted that, although DFT calculations do

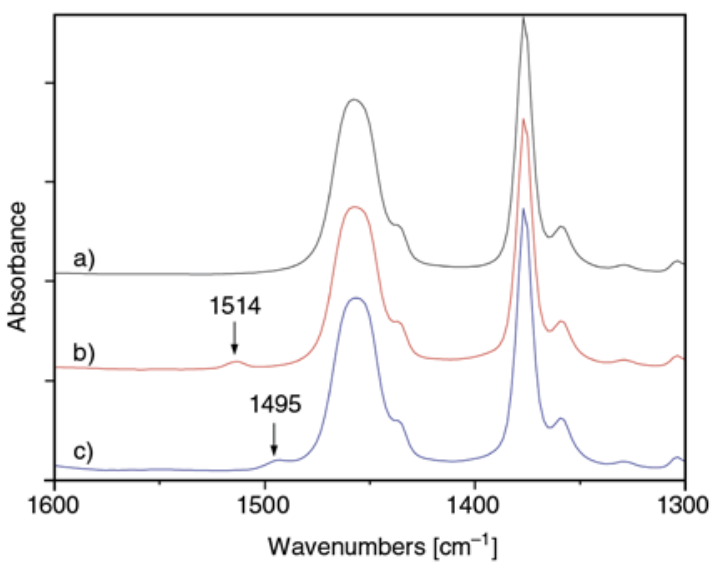

Figure 7. FTIR spectra of the PP/HNT/urea (a), the PP/ HNT/DBMI (b) and the PP/HNT/DBMI/urea (c)

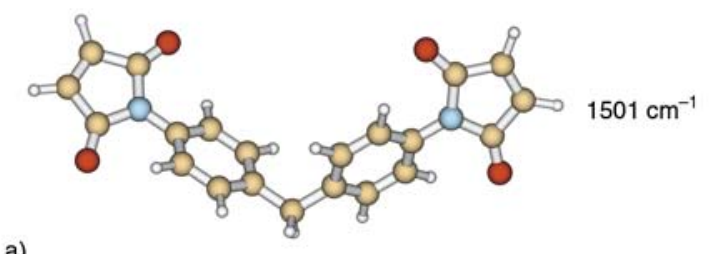

a)
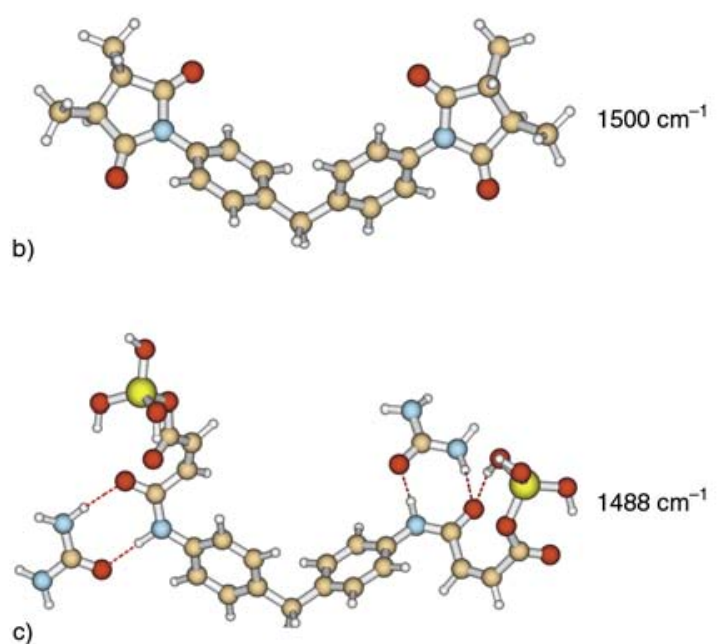

Figure 8. The DFT (B3LYP/6-31G(d)) optimized model structures and calculated frequencies a) imide ring, b) methyl groups added to the imide ring, c) opening of the imide ring

Table 5. Influence of the reactive modifier DBMI on the mechanical properties of the PP/untreated HNT and the PP/HEDA silane- and urea-modified HNT

\begin{tabular}{|l|c|c|}
\hline \multicolumn{1}{|c|}{ Sample } & $\begin{array}{c}\text { Tensile strength } \\
{[\mathbf{M P a}]}\end{array}$ & $\begin{array}{c}\text { Modulus } \\
{[\mathbf{M P a}]}\end{array}$ \\
\hline Neat PP & $36.3 \pm 0.4$ & $1340 \pm 45$ \\
\hline $\mathrm{PP}+5 \mathrm{wt} \%$ untreated HNT & $36.5 \pm 0.4$ & $1440 \pm 84$ \\
\hline $\mathrm{PP}+5 \mathrm{wt} \%$ untreated HNT + 1 wt\% DBMI & $38.6 \pm 0.4$ & $1510 \pm 55$ \\
\hline $\mathrm{PP}+5 \mathrm{wt} \%$ HNT modified HEDA & $36.5 \pm 0.3$ & $1548 \pm 35$ \\
\hline $\mathrm{PP}+5 \mathrm{wt} \%$ HNT modified HEDA + 1 wt\% DBMI & $38.3 \pm 0.4$ & $1527 \pm 95$ \\
\hline $\mathrm{PP}+5 \mathrm{wt} \%$ HNT modified silane & $35.6 \pm 0.2$ & $1495 \pm 65$ \\
\hline $\mathrm{PP}+5 \mathrm{wt} \%$ HNT modified silane + 1 wt\% DBMI & $37.6 \pm 0.4$ & $1580 \pm 45$ \\
\hline PP + 5 wt\% HNT modified urea & $36.5 \pm 0.8$ & $1449 \pm 31$ \\
\hline $\mathrm{PP}+5 \mathrm{wt} \%$ HNT modified urea + 1 wt\% DBMI & $40.0 \pm 0.5$ & $1742 \pm 70$ \\
\hline
\end{tabular}


not reproduce the experimental vibrational frequencies exactly, the relative values of calculated frequencies are reliable and can be used for explanation of the observed frequency shifts. Figure $8 \mathrm{~b}$ demonstrates that a very small frequency change occurs when methyl groups are added to the imide ring. This structure represents a direct reaction of the imide ring with PP, and thus, the band shift observed in Figure 7c cannot be explained by this direct reaction with PP. However, a significant shift in the band to lower wavenumbers $\left(1488 \mathrm{~cm}^{-1}\right)$ was obtained for the model structure representing an opening of the imide ring for the case in which simultaneous hydrogen bonding of urea to the amide group is present (Figure 8c).

The coupling between PP and HNT was further confirmed by Soxhlet extraction in boiling xylene. While the remaining amounts of the PP/HNT and $\mathrm{PP} / \mathrm{BMI} / \mathrm{HNT}$ were approximately $2 \%$ (a portion of the HNT was missed due to 'colloidal' dimensions), the red-colored remainder in the $\mathrm{PP} / \mathrm{BMI} /$ ureaintercalated HNT was $8 \%$. The observed red color serves as further confirmation of the coupling reaction $[29,30]$.

From Table 2 (d-spacing values), it is evident that the increase in PP polarity by DBMI modification supports slightly the intercalation of PP chains into the PP structure. Furthermore, the linking between the PP and the HNT obviously do not support exfoliation. This was confirmed by TEM observation (Figure 6c, 6d), moreover, comparable degree of HNT dispersion was found for all composites studied.

\section{Conclusions}

The results obtained in this study indicate the low impact of single halloysite modifications using ionic exchange, silane condensation and urea intercalation on parameters of $\mathrm{PP} /$ nanocomposites. The most important effects of the modifiers applied include the effect on matrix crystallinity, specifically with respect to HEDA and urea. However, the simultaneous addition of DBMI to all PP/HNT systems resulted in increased mechanical properties due to in situ modification of the matrix, which increased the polarity of matrix and thus the affinity of the PP matrix for the HNT. Moreover, the combination of DBMI with urea-intercalated HNT led to the best mechanical behavior due to coupling between the HNT and the PP via a facilitating reaction between the $\mathrm{OH}$ groups of the HNT and the imide ring of the DBMI by urea.

\section{Acknowledgements}

This work was supported by the Grant Agency of the Academy of Sciences of the Czech Republic (grant No IAA200500904). The financial support of the European Union and the European Social Fund in the frame of the TAMOP-4.2.2/B-10/1-2010-0025 project is also gratefully acknowledged.

\section{References}

[1] Pinnavaia T. J., Beall G. W.: Polymer-clay nanocomposites. Wiley, London (2000).

[2] Bhattacharya S. N., Gupta R. K., Kamal M. R.: Polymeric nanocomposites. Hanser, Munich (2008).

[3] Pavlidou S., Papaspyrides C. D.: A review on polymer-layered silicate nanocomposites. Progress in Polymer Science, 33, 1119-1198 (2008). DOI: $10.1016 /$ j.progpolymsci.2008.07.008

[4] Du M., Guo B., Jia D.: Newly emerging applications of halloysite nanotubes: A review. Polymer International, 59, 574-582 (2010).

DOI: $10.1002 /$ pi.2754

[5] Rawtani D., Agrawal Y. K.: Multifarious applications of halloysite nanotubes: A review. Reviews on Advanced Materials Science, 30, 282-295 (2012).

[6] Nicolini K. P., Fukamachi C. R. B., Wypych F., Mangrich A. S.: Dehydrated halloysite intercalated mechanochemically with urea: Thermal behavior and structural aspects. Journal of Colloid and Interface Science, 338, 474-479 (2009).

DOI: $10.1016 /$ j.jcis.2009.06.058

[7] Brindley G. W., Robinson K.: Randomness in the structures of kaolinitic clay minerals. Transactions of the Faraday Society, 42, 198-205 (1946).

DOI: $10.1039 / \mathrm{TF} 946420 \mathrm{~B} 198$

[8] Joussein E., Petit S., Churchman J., Theng B., Righi D., Delvaux B.: Halloysite clay minerals - A review. Clay Minerals, 40, 383-426 (2005).

DOI: $10.1180 / 0009855054040180$

[9] Liu C., Luo Y., Jia Z., Li S., Guo B., Jia D.: Structure and properties of poly(vinyl chloride)/halloysite nanotubes nanocomposites. Journal of Macromolecular Science Part B: Physics, 51, 968-981 (2012).

DOI: $10.1080 / 00222348.2011 .564106$

[10] Liu C., Luo Y. F., Jia Z. X., Zhong B. C., Li S. Q., Guo B. C., Jia D. M.: Enhancement of mechanical properties of poly(vinyl chloride) with polymethyl methacrylate-grafted halloysite nanotube. Express Polymer Letters, 5, 591-603 (2011).

DOI: $\underline{10.3144 / \text { expresspolymlett.2011.58 }}$ 
[11] Lecouvet B., Gutierrez J. G., Sclavons M., Bailly C.: Structure-property relationships in polyamide 12 /halloysite nanotube nanocomposites. Polymer Degradation and Stability, 96, 226-235 (2011).

DOI: $10.1016 /$ j.polymdegradstab.2010.11.006

[12] Handge U. A., Hedicke-Höchstötter K., Altstädt V.: Composites of polyamide 6 and silicate nanotubes of the mineral halloysite: Influence of molecular weight on thermal, mechanical and rheological properties. Polymer, 51, 2690-2699 (2010).

DOI: $10.1016 /$ j.polymer.2010.04.041

[13] Liu M., Guo B., Du M., Lei Y., Jia D.: Natural inorganic nanotubes reinforced epoxy resin nanocomposites. Journal of Polymer Research, 15, 205-212 (2008). DOI: $10.1007 / \mathrm{s} 10965-007-9160-4$

[14] Barrientos-Ramírez S., de Oca-Ramírez G. M., Ramos-Fernández E. V., Sepúlveda-Escribano A., Pastor-Blas M. M., González-Montiel A.: Surface modification of natural halloysite clay nanotubes with aminosilanes. Application as catalyst supports in the atom transfer radical polymerization of methyl methacrylate. Applied Catalysis A: General, 406, 22-33 (2011). DOI: $10.1016 /$ j.apcata.2011.08.003

[15] Du M., Guo B., Cai X. J., Jia Z., Liu M., Jia D.: Morphology and properties of halloysite nanotubes reinforced polypropylene nanocomposites. e-Polymers, no. 130 (2008).

[16] Lecouvet B., Sclavons M., Bourbigot S., Devaux J., Bailly C.: Water-assisted extrusion as a novel processing route to prepare polypropylene/halloysite nanotube nanocomposites: Structure and properties. Polymer, 52, 4284-4295 (2011).

DOI: $10.1016 /$ j.polymer.2011.07.021

[17] Du M., Guo B., Liu M., Jia D.: Thermal decomposition and oxidation ageing behaviour of polypropylene/halloysite nanotube nanocomposites. Polymers and Polymer Composites, 15, 321-328 (2007).

[18] Pasbakhsh P., Ismail H., Fauzi M. N. A., Abu Bakar A.: EPDM/modified halloysite nanocomposites. Applied Clay Science, 48, 405-413 (2010).

DOI: $10.1016 /$ j.clay.2010.01.015

[19] Prashantha K., Lacrampe M. F., Krawczak P.: Processing and characterization of halloysite nanotubes filled polypropylene nanocomposites based on a masterbatch route: Effect of halloysites treatment on structural and mechanical properties. Express Polymer Letters, 5, 295-307 (2011).

DOI: $10.3144 /$ expresspolymlett.2011.30

[20] Jia Z., Luo Y., Guo B., Yang B., Du M., Jia D.: Reinforcing and flame-retardant effects of halloysite nanotubes on LLDPE. Polymer-Plastics Technology and Engineering, 48, 607-613 (2009). DOI: $10.1080 / 03602550902824440$

[21] Liu M., Jia Z., Liu F., Jia D., Guo B.: Tailoring the wettability of polypropylene surfaces with halloysite nanotubes. Journal of Colloid and Interface Science, 350, 186-193 (2010).

DOI: $10.1016 /$ j.jcis.2010.06.047
[22] Du M., Guo B., Jia D.: Thermal stability and flame retardant effects of halloysite nanotubes on poly(propylene). European Polymer Journal, 42, 1362-1369 (2006).

DOI: $\underline{10.1016 / j . e u r p o l y m j .2005 .12 .006}$

[23] Liu M., Guo B., Lei Y., Du M., Jia D.: Benzothiazole sulfide compatibilized polypropylene/halloysite nanotubes composites. Applied Surface Science, 255, 4961-4969 (2009).

DOI: $10.1016 /$ j.apsusc.2008.12.044

[24] Liu M., Guo B., Du M., Jia D.: The role of interactions between halloysite nanotubes and 2,2'-(1,2-ethenediyldi4,1-phenylene) bisbenzoxazole in halloysite reinforced polypropylene composites. Polymer Journal, 40, 1087-1093 (2008). DOI: 10.1295/polymj.PJ2008133

[25] Liu M., Guo B., Du M., Zou Q., Jia D.: Influence of hybrid fibrils of 2,5-bis(2-benzoxazolyl) thiophene and halloysite nanotubes on the crystallization behaviour of polypropylene. Journal of Physics D: Applied Physics, 42, 075306/1-075306/9 (2009). DOI: $10.1088 / 0022-3727 / 42 / 7 / 075306$

[26] Ning N-Y., Yin Q-J., Luo F., Zhang Q., Du R., Fu Q.: Crystallization behavior and mechanical properties of polypropylene/halloysite composites. Polymer, 48, 7374-7384 (2007).

DOI: 10.1016/j.polymer.2007.10.005

[27] Khunová V., Kelnar I., Liauw C. M., Lukác P.: The effect of interfacial modification on the properties of reactively processed polypropylene/clay nanocomposites. Composite Interfaces, 18, 357-370 (2011). DOI: $\underline{10.1163 / 092764411 X 584496}$

[28] Khunová V., Liauw C. M., Kelnar I., Snauko M.: Elimination of separation processes for post-consumer polyolefin waste: Reactive blending using 1,3-phenylene dimaleimide in presence of filler. Macromolecular Materials and Engineering, 294, 502-509 (2009).

DOI: $10.1002 /$ mame.200900025

[29] Liauw C. M., Khunová V., Lees G. C., Rothon R. N.: Reactively processed high performance impact modified polypropylene/magnesium hydroxide composites: Interfacial studies. Macromolecular Symposia, 194, 191-200 (2003).

DOI: $10.1002 /$ masy.200390082

[30] Khunová V., Liauw C. M.: Tailoring of interphase structure in highly filled poly(propene) block copolymer via reactive processing. Polymer Bulletin, 47, 465-473 (2002).

DOI: $10.1007 / \mathrm{s} 002890200010$

[31] Irikura K. K., Johnson R. D. III, Kacker R. N.: Uncertainties in scaling factors for ab initio vibrational frequencies. Journal of Physical Chemistry A, 109, 84308437 (2005).

DOI: $10.1021 / \mathrm{jp} 052793 \mathrm{n}$ 